\title{
Effect on uropathogens of prophylaxis for urinary tract infection in spinal cord injured patients: preliminary study
}

\author{
Gregor Reid ${ }^{1,2}$ and Lesley Howard ${ }^{3}$ \\ ${ }^{1}$ Department of Microbiology and Immunology, The University of Western Ontario; ${ }^{2}$ Lawson Research Institute, \\ London, Ontario, N6A 4V2, Canada; ${ }^{3}$ Registered Nurse, Public Hospital, Dunedin, New Zealand
}

\begin{abstract}
Spinal cord injured patients are highly prone to urinary tract infections. The high frequency of recurrences, the problems with drug resistance and the difficulties associated with diagnosis complicate the management. In a preliminary retrospective study of 30 patient files, we discovered that prophylactic antimicrobial therapy with trimethoprim-sulfamethoxazole, significantly reduced the incidence of symptomatic urinary tract infections. The prevention of infection resulted in cheaper healthcare expenses than treatment. One problematic outcome was that antibiotic therapy resulted in a dramatic change in the population of uropathogens infecting the host, from a predominantly Gram negative type to one dominated by Enterococcus faecalis.
\end{abstract}

Keywords: spinal cord injured; bacteriuria; urinary tract infection; prophylactic antimicrobial therapy

\section{Introduction}

Urinary tract infections (UTI) are a common problem in those patients with a spinal cord injury and a neuropathic bladder. The use of intermittent catheterization has improved the care of these patients, but infections still arise, and the dilemma facing the urologist or physician is whether or not to administer antibiotic therapy. The problem is complicated by the anticipated rise in drug resistance of organisms exposed to antibiotics, and by the ability of bacteria to form biofilms on bladder cells and thence resist the action of antimicrobial agents. ${ }^{1}$ While trimethoprimsulfamethoxazole (TMPSMX) is used to prevent UTI in otherwise healthy adult females, it has not been shown to reduce the rate of UTI in neurogenic bladder patients. ${ }^{2}$

The aim of the present study was to examine retrospectively files from 30 spinal cord injured patients using intermittent catheterization to manage urinary voiding, and determine whether UTI occurred less often with the receipt of prophylactic antimicrobial therapy.

\section{Materials and methods}

Study population and process of evaluation of records Records from a total of 30 spinal cord injured patients (mean age 38 , range 12 to $80 ; 22$ males, 8 females; 15

Correspondence: G Reid, H414, Lawson Research Institute, 268 Grosvenor Street, London, Ontario, N6A 4V2, Canada tetraplegic, 14 paraplegic, one defined as having cervical myelopathy) all using intermittent catheterization to manage bladder voiding, were studied retrospectively for periods of up to 32 weeks. The study noted the number of urinary tract infections detected $\left(>10^{5}\right.$ colony forming units per $\mathrm{ml}$ urine, plus signs and/or symptoms of infection, including fever, malaise, spasticity, hematuria, pyuria), the outcome of therapy, and the cost benefit analysis. All but eight patients received prophylactic therapy during one or more weeks of study. Institutional ethics approval was granted. Intermittent catheter urine specimens were cultured, using standard microbiological media and techniques, at regular intervals (at least weekly).

\section{Results}

The results presented in Table 1 show several important findings. The incidence of UTI was significantly lower $(P=0.001)$ when the patients received prophylactic therapy. TMPSMX was the most commonly prescribed for prophylaxis (139 weeks out of 157), and its usage reduced the infection rate. Nitrofurantoin was used prophylactically in the remaining cases, but the data were too few to analyze conclusively.

There was a significant change in the infecting organism post use of TMPSMX prophylaxis, in that the occurrence of $E$. faecalis rose two fold and that of $E$. coli dropped threefold. This is illustrated in Figure 1, which admittedly is only one case, but it demonstrates the complexity of analysing drug therapy 
Table 1 Results of the study of 30 spinal cord injured patients

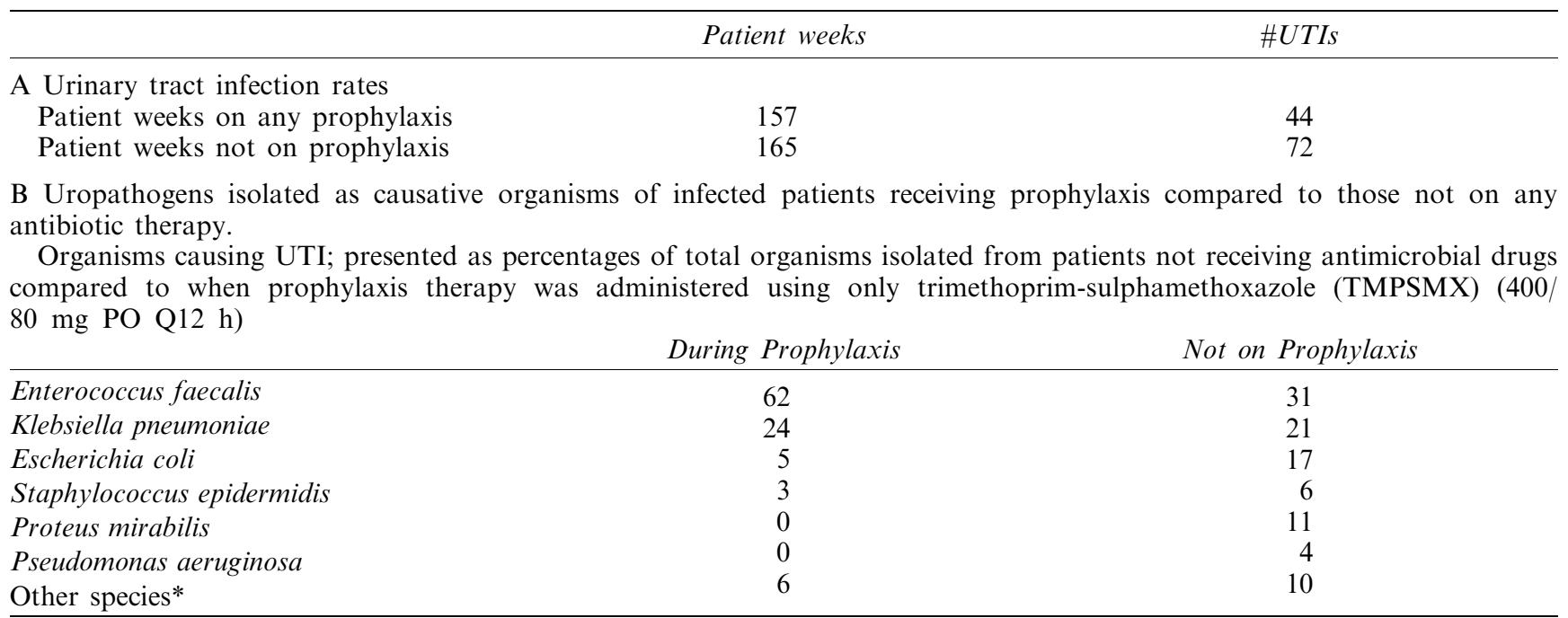

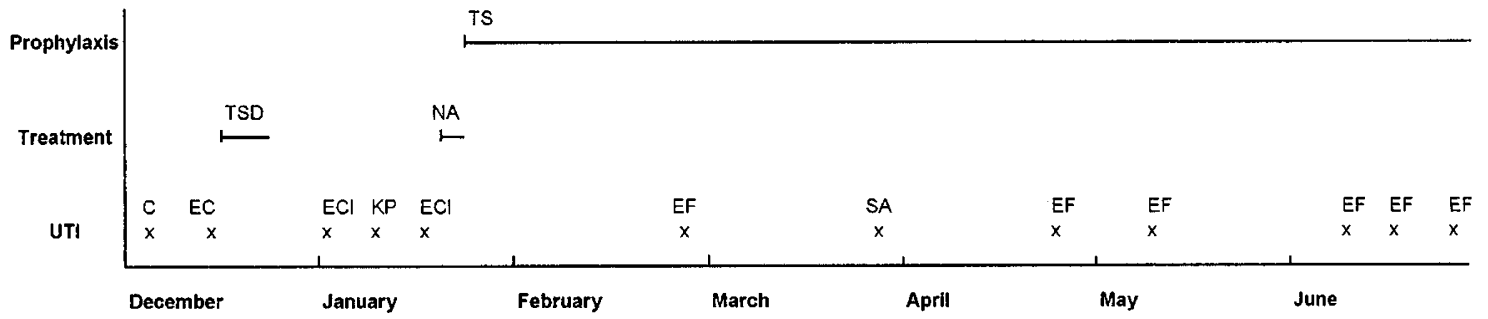

Figure 1 Record of symptomatic UTI and antibiotic therapy for a 32 year old female quadraplegic using intermittent catherization. $\mathrm{C}=$ Citrobacter sp.; $\mathrm{EC}=\mathrm{E}$. coli; $\mathrm{E} . \mathrm{CI}=$ Enterobacter cloacae; $\mathrm{KP}=$ Klebsiella pneumoniae; $\mathrm{EF}=\mathrm{Enterococcus}$ faecalis; $\mathrm{SA}=\mathrm{S}$. aureus; $\mathrm{TSD}=$ Trimethoprim sulfamethoxazole double strength; $\mathrm{MA}=$ naladixic acid; $\mathrm{TS}=$ Trimethoprim sulfamethoxazole.

in this population. Overall, the incidence of Gram negative uropathogens causing UTI fell from $63 \%$ to $35 \%$ during prophylaxis. Of the infections that arose during TMPSMX prophylaxis, $100 \%$ enterococci, staphylococci and $K$. pneumoniae were resistant to TMPSMX, and $100 \%$ E. coli were sensitive.

Fifty UTIs $\left(>10^{5}\right.$ bacteria per $\mathrm{ml}$ urine plus signs and symptoms) were actually treated with therapeutic dosages of antimicrobial agents, resulting in $76 \%$ success, as defined by sterile urine within the first week of completion of therapy. Fluoroquinolones ciprofloxacin (500 $\mathrm{mg}$ po Q12 h) and particularly norfloxacin $(400 \mathrm{mg}$ po Q12 h) were the most commonly used $(32 \%)$ agents to treat infection; others were cefotaxime (500 mg Q6 $\mathrm{h} \times 7$ days), trimethoprim-sulphamethoxazole (TMPSMX: Q12 $\mathrm{h} \times 7$ days), nalidixic acid (100 mg Q6 $\mathrm{h} \times 10$ days), cefaclor $(250 \mathrm{mg}$ Q8 $\mathrm{h} \times 7$ days), cefuroxime (1000 iv Q8 $\mathrm{h} \times 1$ day), cefotaxime ( $1 \mathrm{~g}$ iv $\mathrm{Q} 8 \mathrm{~h} \times 5$ days), gentamycin $(100 \mathrm{mg}$ iv $\mathrm{Q} 8 \mathrm{~h} \times 7$ days), amoxycillin (250 mg Q6 $\mathrm{h} \times 7$ days), cloxacillin (250 mg Q6 $\mathrm{h} \times 10$ days), ampicillin $(500 \mathrm{mg}$ Q6 $\mathrm{h} \times 7$ days), nitrofurantoin (100 $\mathrm{mg}$ Q6 $\mathrm{h} \times 10$ days), erythromycin $(500 \mathrm{mg}$ Q6 $\mathrm{h} \times 7$ days), tobramycin $(60 \mathrm{mg}$ iv $\mathrm{Q} 8 \mathrm{~h} \times 10$ days) and vancomycin $(125 \mathrm{mg}$ iv Q6 $\mathrm{h} \times 10$ days).

Five male patients (three tetraplegic, two paraplegic, aged 16, 19, 26, 29 and 65), had especially high infection rates (average of 0.8 UTIs per week for up to 16 weeks) emphasizing the severity of the problem. An analysis of the 30 patients showed that there was no difference in the time to first infection when the patients were off therapy (average 2.83 weeks) or receiving prophylaxis (2.82 weeks).

The use of prophylactic TMPSMX in our study cost $\$ 156$ Can for 139 patient weeks, while the active therapy to treat UTI cost $\$ 1,222$ Can for 50 weeks.

\section{Discussion}

This study, albeit preliminary in the sense of a reasonably short follow-up, demonstrates the complicated nature of urinary tract infection in the spinal 
cord injured patient population. The incidence of UTI was lowered significantly $(P<0.001)$ with the use of TMPSMX prophylaxis, in agreement with another study of patients who used clean intermittent catheterization. $^{3}$

However, time to first infection did not differ, thereby suggesting that TMPSMX prophylaxis should not be used upon immediate entry of the patients to a rehabilitation centre. Another important reason for reaching this conclusion, was the increased prevalence of drug resistant enterococci following prophylaxis with TMPSMX. The emergence of enterococci resistant to TMPSMX is consistent with our studies of UTI in adult females in suburban Toronto which show these organisms to be the second most common cause of infection (manuscript submitted). These organisms are known to harbour vancomycin resistance, ${ }^{4}$ and indeed, one of the strains in this study was resistant, and over half of the others were only moderately sensitive to vancomycin, implying their tendency to complete resistance.

Another important factor which is not a component of standard retrospective, or even prospective studies related to UTI, is the ability of enterococci and other uropathogens to develop as biofilms on the surface of bladder cells. ${ }^{5}$ These biofilms are highly resistant to antimicrobial therapy, perhaps explaining why so many infections arose in this patient group. Also, TMPSMX does not seem able to eradicate uropathogenic biofilms, ${ }^{6}$ again raising questions about usage of this agent in the setting of SCI patients. Studies have shown that fluoroquinolones can, to a large extent, eradicate biofilms on bladder cells and the surfaces of biomaterials. $^{6,7}$ Thus, norfloxacin or other fluoroquinolones form an important part of the armamentarium to treat bacteria in biofilms.

The increasing fiscal constraints facing many countries including Canada, UK and USA, mean that health expenditure is an important consideration, as well as patient outcome, in determining the best therapeutic management. Indeed, cost-effectiveness associated with the use of cheap prophylactic agents is regarded as an important extra dimension in evaluation of treatment by surgeons. ${ }^{8}$ In the present study, it was more economical to prevent infection, based upon the cost of drugs, as well as factoring in the laboratory, nursing and physician costs to care for a patient with UTI, plus the cost of hospital stay as a consequence of delayed rehabilitation of the patient.

Drug usage per se will not solve completely the problem of repeated infections in these patients, and it may coincide with emergence of multiresistant uropathogens. $^{9}$ Nevertheless, if prophylaxis reduces health care costs and provides quality medical care, it's usage cannot be discounted.

\section{Acknowledgements}

The support of Merck Frosst Canada, the Medical Research Council of Canada, and the assistance of researchers and patients at Parkwood Hospital, and Ms Y Kang and Mr G McKinley is appreciated.

\section{References}

1 Reid G. Do antibiotics clear bladder infections? J Urol 1994; 152: 865.

2 Mohler JL, Cowen DL, Flanigan RC. Suppression and treatment of urinary tract infection in patients with an intermittently catheterized neurogenic bladder. J Urol 1987; 138: 336.

3 Bakke A, Vollset SE. Risk factors for bacteriuria and clinical urinary tract infection in patients treated with clean intermittent catheterization. J Urol 1993; 149: 527.

4 Willey BM et al. Detection of vancomycin resistance in Enterococcus species. J Clin Microbiol 1992; 30: 1621.

5 Reid G et al. Bacterial biofilm formation in the urinary bladder of spinal cord injured patients. Paraplegia 1992; 30: 711 .

6 Reid $\mathrm{G}$ et al. Ability of fluoroquinolones to penetrate bacterial biofilms on bladder cells of spinal cord injured patients. Paraplegia 1994; 32: 468.

7 Reid G et al. Effect of ciprofloxacin, norfloxacin and ofloxacin in vitro on the adhesion and survival of Pseudomonas aeruginosa on urinary catheters. Antimicrob Agents Chemother 1994; 38: 1490.

8 Davey P, Malek M, Thomas P. Measuring the cost-effectiveness of antibiotic prophylaxis in surgery. Am J Surg 1992; 164 Suppl 4A: 39S.

9 Simor AE et al. Molecular and epidemiologic study of multiresistant Serratia marcescens infections in a spinal cord injury rehabilitation unit. Infect. Control Hosp Epidemiol 1988; 9: 20. 